\title{
The Hypoglycaemic, Antihyperlipidemic and Antioxidative Effects of Anacardium Occidentale Methanolic Nut Extract in Streptozotocin-Induced Diabetic Male Wistar Rats
}

\author{
Folasade 0. AJAO ( $\square$ foajao@lautech.edu.ng ) \\ Ladoke Akintola University of Technology Faculty of Basic Medical Sciences \\ Michael A. Olamoyegun \\ Ladoke Akintola University of Technology Faculty of Basic Medical Sciences \\ Marcus O. lyedupe \\ Ladoke Akintola University of Technology Faculty of Basic Medical Sciences
}

\section{Research}

Keywords: Anacardium occidentale, Diabetes, Dyslipidemia, Oxidative stress, Liver

Posted Date: March 11th, 2021

DOI: https://doi.org/10.21203/rs.3.rs-281201/v1

License: @ (i) This work is licensed under a Creative Commons Attribution 4.0 International License. Read Full License 


\section{Abstract}

Background: This research work investigated the antidiabetic, anti-hyperlipidemic, and antioxidative effects of Anacardium occidentale methanolic nut extract in Streptozotocin (STZ)-induced diabetic Wistar rats.

Methods: Forty (40) Wistar rats weighing $250 \pm 30 \mathrm{~g}$ were randomly divided into five groups of 8 rats each. Group 1 served as the control; Group 2-5 were induced with diabetes with a single dose of $50 \mathrm{mg} / \mathrm{kg}$ bw of streptozotocin intraperitoneally. After diabetes induction, Group 2 served as the STZ-only group, Groups 3 and 4 were administered $100 \mathrm{mg} / \mathrm{kg}$ bw and $200 \mathrm{mg} / \mathrm{kg}$ bw p.o Anacardium occidentale nut extract, respectively, while Group 5 was administered $2 \mathrm{mg} / \mathrm{kg}$ bw of glimepiride as a reference drug for a period of 4 weeks. Food and water intake were monitored daily, body weight, and blood glucose levels weekly throughout the experiment. On day 29 , the animals were sacrificed, and blood samples were collected through cardiac puncture for biochemical studies.

Results: Administration of the nut extract significantly $(p<0.05)$ increased the food intake and body weight of diabetic treated rats, fasting blood glucose level and oral glucose tolerance test (OGTT) decreased significantly $(p<0.05)$ in treated rats. On lipid profile, administration of nut extract significantly decreased $(p<0.05)$ triglyceride, low-density lipoprotein, total cholesterol, and very-low-density lipoprotein concentrations while it significantly increases $(p<0.05)$ the high-density lipoprotein. Anacardium occidentale nut extract caused significantly $(p<0.05)$ increases in SOD, GPx, GSH, and CAT levels with a decrease MDA level in diabetic treated rats. Markers of liver and kidney functions were also improved in diabetic treated rats.

Conclusion: Treatment with Anacardium occidentale methanolic nut extract has hypoglycemic, hypolipidemic, and hepato-protective effects in diabetic rats. It also alleviates oxidative stress activity and restoration of markers of kidney function, and may be useful as alternative therapy in the management of diabetes and its related complications.

\subsection{Background}

Diabetes mellitus is a cluster of metabolic diseases characterized by hyperglycemia as a result of abnormal secretion and action of insulin or both. Globally the incidence of the disease is escalating. In 2017, about 425 million individuals suffered from diabetes worldwide, with a projection that about 630 million people will be affected by the disease by the year 2030 [1]. Approximately 14.7 million adults suffer from diabetes in Africa, with Nigeria having the highest and a consistent rise in mortality rate [2].

Chronic hyperglycemia leads to long-term damage and malfunctioning of various organs of the body [3]. Diabetes-specific microvascular disease is a leading cause of blindness, renal failure, and nerve damage [4, 5]. Long-term hyperglycemia in diabetes mellitus also generates reactive oxygen species (ROS), which destroys the cells with resultant secondary complications [6]. This elevation in the ROS level could be due to a decrease in destruction and/or increase in catalase (CAT), superoxide dismutase (SOD), and glutathione peroxidase (GSH$\mathrm{Px}$ ) antioxidants production. The altered levels of these enzymes make the tissues susceptible to oxidative stress leading to the development of diabetic complications [7]. According to epidemiological studies, diabetic mortalities can be explained notably by an increase in vascular diseases other than hyperglycemia [8]. 
The uptake of glucose by cells and metabolic utilization is disrupted, and the conversion of excess glucose to either glycogen in the liver or as fat for storage is usually decreased compared to non-diabetic persons. Hyperlipidemia is common in diabetes mellitus [9] especially elevated triglyceride and cholesterol levels. Hypercholesterolemia is one of the risk factors responsible for the onset of the development of atherosclerosis during the course of diabetes mellitus [10].

Oral hypoglycemic drugs used in management of these diseases have side effects such as gastrointestinal discomfort, weight gain, and hepatic dysfunction [11]. Therefore, there is an increasing need to find more safe and efficient therapies for prevent diabetes mellitus and its related complications. Plants are known to possess a wide variety of pharmacological effects and extraordinary therapeutic possibilities.

The Cashew tree, also known as Anacardium occidentale (Latin name), is a member of the Anacardiaceae family. Anacardium occidentale is grown widely in tropical countries like Malaysia, India, Brazil, Nigeria, and occurs widely in Senegal and is known as Darkassou [12].

The stem bark, fruits, and leaf extract, have pharmaceutical properties and extensively used as antiinflammatory, antioxidant, antibacterial, and antidiarrheal [13-16]. The anti-diabetic and anti- inflammatory properties have also been reported [17]. Phytochemical study of the methanolic leave extract revealed the presence of phenolic, flavonoids, steroids and triterpenes [18]. The hypoglycemic effect of the administration of methanol plant extract at a single dose of $800.0 \mathrm{mg} / \mathrm{kg}$ bw was found to be more pronounced than that of the aqueous extract in both the normal and streptozotocin-diabetic rats [19]. Thus, the current study was aimed at investigating the antidiabetic, anti-hyperlipidemic, and antioxidative effects of Anacardium occidentale methanolic nut extract in Streptozotocin (STZ)-induced diabetic rats.

\subsection{Methods}

\section{$2.1 \quad$ Animals}

Healthy male Wistar rats $(180 \mathrm{~g} \pm 20 \mathrm{~g})$ were used. The animals were received from the Animal House of Physiology Department, Ladoke Akintola University of Technology, Ogbomoso, Oyo State, Nigeria. Rats were housed in a plastic cage ( 8 rats per cage) under controlled conditions of temperature $\left(25 \pm 2^{\circ} \mathrm{C}\right)$, humidity $(45 \%+$ $5 \%)$ and light (12 $\mathrm{h}$ light/dark cycles). The animals were fed with rat pellets (Premier Feed Ltd. Ibadan) and water ad libitum and were acclimatized for 1 weeks prior to the initiation of the experiment. All procedures were approved by the Animal Care Committee of Ladoke Akintola University of Technology. All experimental protocols and handling of the animals were following the Guide for the Care and Use of Laboratory Animals [20].

\subsection{Plant materials}

Anacardium occidentale nuts were obtained from plants grown at Ladoke Akintola University of Technology (LAUTECH) farm, Ogbomoso, Oyo state. The plant was identified and authenticated by Dr A. T. J. Ogunkunle, Biology Department, Ladoke Akintola University of Technology, Ogbomoso, Oyo state, and a voucher specimen number of LHO 533 was given.

\subsection{Plant extraction}


The nut of Anacardium occidentale plant was sun-dried at room temperature in the laboratory, powdered and stored in airtight container. The powdered nut of Anacardium occidentale was extracted with $95 \%$ ethanol in the Soxhlet apparatus [21].

\subsection{Phytochemical Analysis}

Anacardium occidentale nut extracts were subjected to preliminary phytochemical screening for the presence of alkaloids, quinines, resins, tannins, fixed oils, flavonoids, fats, saponins, phenolic compounds, Proteins and carboxylic acids using the procedures outlined by Sofowora; Trease and Evans [22,23].

\subsection{Acute toxicity test}

Acute toxicity test was carried out according to the modified Lorke's method [24] using a total of 12 rats. At the initial phase, the rats were assigned randomly into three groups of 3 rats each. The rats in each group were administered an intraperitoneal injection of extract at 10,100, and $1000 \mathrm{mg} / \mathrm{kg}$. Their body weight was observed for signs of toxicity and death in the first 24hours. In the second phase, another set of rats were randomly assigned into four groups of one rat each and administered the Anacardium occidentale methanolic nut extract intraperitoneally, at 1600,2900 , and $5000 \mathrm{mg} / \mathrm{kg}$ based on the result of the first phase. The $\mathrm{LD}_{50}$ was then calculated as the square root of the product of the maximum dose for all surviving and minimum dose for all mortality using the formula;

$\mathrm{LD}_{50}=(\mathrm{D} \otimes \mathrm{X} \mathrm{D} \otimes \mathbb{Q} \otimes)$

\subsection{Experimental induction of diabetes}

Diabetes was induced through a single intraperitoneal injection of (50 mg/ kg b.w.) freshly prepared streptozotocin (STZ) in $0.1 \mathrm{M}$ citrate buffer $(\mathrm{pH}=4.5)$ to overnight fasted rats [25]. To prevent the initial drug induced hypoglycemic death, diabetic rats were permitted to drink a $20 \%$ glucose solution overnight. The blood glucose level was measured after three days, and rats with glucose levels $>200 \mathrm{mg} / \mathrm{dL}$ were considered as diabetic. Control rats however injected with $0.2 \mathrm{~mL}$ of the vehicle $(0.1 \mathrm{M}$ citrate buffer, $\mathrm{pH} 4.5)$ alone.

\subsection{Experimental Design}

A total of 40 experimental rats were used to assess the effect of the nut extracts on the experimental rats: 32 STZ induced diabetic rats plus 8 normal control rats. Animals were divided into five (5) major groups and housed under controlled environmental conditions. Rats were divided into the following groups:

Group 1: Control (CON)

Group 2: STZ induced diabetic rats (STZ)

Group 3: STZ induced diabetic rats + nut extract Anacardium occidentale (100 mg $/ \mathrm{kg}$ b.w.)

Group 4: STZ induced diabetic rats + nut extract Anacardium occidentale $(200 \mathrm{mg} / \mathrm{kg} \mathrm{b.w.})$

Group 5: STZ induced diabetic rats $+2 \mathrm{mg} / \mathrm{kg}$ b.w. Glimepiramide (GMP) 


\subsection{Assessment of Fasting Plasma Glucose Levels and Body Weight Measurement}

The body weight measurement and fasting plasma glucose levels were assessed before and during the administration of the extracts weekly, till the end of the study. The glucose level in plasma was determined by glucose oxidase/peroxidase method as described by [26] using a digital glucometer and test strips (Accu-Chek Advantage, Roche Diagnostic, Germany)

\subsection{Biochemical Parameters}

At the end of the experimental treatment, after $12 \mathrm{~h}$ fasting, the animals were anaesthetized with ketamine$75 \mathrm{mg} / \mathrm{kg}$ and xylazine- $20 \mathrm{mg} / \mathrm{kg}$ intraperitoneal injection. The unconscious animals were sacrificed by cervical dislocation and the hearts were exposed by thoracotomy. The fasting blood was collected via cardiac punctured into heparinized tubes, centrifuged at $13000 \mathrm{rpm}$ for $5 \mathrm{mins}$, and the plasma was then retrieved. The

plasma determination of plasma total cholesterol (TC), triglycerides (TG) and HDL-cholesterol, was done using a commercial Diagnostic Kit (Genzyme Diagnostics, MA. USA).

Antioxidant enzyme activities in the plasma were assayed using commercial kits: Serum GSH was measured based on the method described by [27]. Serum MDA, SOD, and GPx levels were measured by enzyme-linked immunosorbent assay (ELISA) methods using Rat MDA, SOD, and GPx Elisa Kit (Elabscince, China).

Markers of kidney function (blood urea nitrogen (BUN), plasma creatinine, and uric acid) were determined by using the commercially kits from Siemens Health Care Diagnostics. The liver biomarkers such as Aspartate aminotransferase (AST), Alanine aminotransferase (ALT), Alkaline phosphatase (ALP), Total protein (TP), and Albumin were assayed in plasma spectrophotometrically by standard automated techniques according to the procedures described by the manufacturers.

\subsection{Statistical analysis}

Data statistical analysis was carried out using SPSS, Version 21 software. The results were expressed as mean \pm SEM, and the statistical difference was evaluated using one-way analysis of variance (ANOVA) followed by Bonferroni post hoc test. Data were considered statistically significant at $p$ less than $0.05(p<0.05)$

\subsection{Results}

\subsection{Preliminary phytochemical screening of methanolic extract of Anacardium occidentale nut}

The Anacardium occidentale nut extract was screened for the different classes of secondary metabolites. Tests for saponins, tannins, steroid, terpenoid, cardiac glycosides, phlobatanins, flavonoids, anthraquinones, alkaloids and carbohydrates were carried out. Tannins, terpenoids, and reducing sugar all tested positive while Saponins, phlobatamins, cardiac glycosides, anthraquinones, alkaloids, flavonoids and steroids tested negative (Table 1).

\subsection{Effects of Anacardium occidetale nut extract on water intake in streptozotocin-induced diabetic rats}

Figure 1 shows the water intake of control and treated rats after administration of Anacardium occidentale nut extract. There was a significant increase $(p<0.05)$ in the water intake of diabetic rats when compared with the 
control. Administration of $100 \mathrm{mg} / \mathrm{kg}$ body weight and $200 \mathrm{mg} / \mathrm{kg}$ body weight of Anacardium occidentale nut extract and glimepiride significantly decrease water intake in groups 3,4 and 5 compared to the diabetic group.

\subsection{Effects of Anacardium occidetalenut extract on food intake in streptozotocin-induced diabetic rats}

Figure 2 shows the food intake of control and treated rats after administration of Anacardium occidentalenut extract. There was a significant decrease $(p<0.05)$ in the food intake of diabetic rats when compared with the control. Administration of $100 \mathrm{mg} / \mathrm{kg}$ body weight and $200 \mathrm{mg} / \mathrm{kg}$ body weight of Anacardium occidentale nut extract and glimepiride significantly increase food intake in groups 3, 4 and 5 compared to the diabetic group.

\subsection{Effects of Anacardium occidentale nut extract on fasting blood glucose in streptozotocin-induced diabetic rats}

Figure 3 shows the fasting blood glucose of control and treated rats after administration of Anacardium occidentale nut extract. There was a significant increase $(p<0.05)$ in the fasting blood glucose of diabetic rats when compared with the control. Administration of $100 \mathrm{mg} / \mathrm{kg}$ body weight and $200 \mathrm{mg} / \mathrm{kg}$ body weight of Anarcadium occidentale nut extract and glimepiride ameliorates the increase in fasting blood glucose in groups 3,4 and 5 compared to the diabetic group.

\subsection{Effects of anarcardium occidetale nut extract on body weight in streptozotocin-induced diabetic rats}

Figure 4 shows the body weight of control and treated rats after administration of Anacardium occidentale nut extract. There was a significant decrease $(p<0.05)$ in the body weight of diabetic rats when compared with the control. Administration of $100 \mathrm{mg} / \mathrm{kg}$ body weight and $200 \mathrm{mg} / \mathrm{kg}$ body weight of Anacardium occidentale nut extract and glimepiride attenuates the decreased body weight in groups 3,4 and 5 compared to the diabetic group.

\subsection{Assessment of weekly blood glucose level in streptozotocin-induced diabetic rats}

In figure 5, blood glucose level of control group was $86.5 \pm 4.5 \mathrm{mg} / \mathrm{dl}$ while that of the diabetic groups increased significantly when compared with control induction of diabetes (Day 1) Blood glucose in the diabetic rats treated with $100 \mathrm{mg} / \mathrm{kg}$ and $200 \mathrm{mg} / \mathrm{kg}$ of Anacardium occidentale nut extract and $2 \mathrm{mg} / \mathrm{kg}$ Glimepiride (GMP) respectively decreased when compared with diabetic non-treated rats on Days 7, 14, 21 and 28 of the experiment.

\subsection{Effect of Anacardium occidentale nut extract on Antioxidant Enzymes and}

\section{Oxidative Stress Parameters in streptozotocin-induced male Diabetic rats.}

Table 2 illustrates the oxidative stress indices assessed in experimental rats. The superoxide dismutase activity (SOD), catalase level (CAT), glutathione peroxidase (GPx) and reduced glutathione (GSH) activity in the STZ group decreased significantly while malondialdehyde (MDA) level was increased significantly when compared to control. After treatment, there was significant increase in enzyme activity of glutathione peroxidase in the extract $(p<0.05)$ and GMP $(p<0.01)$ treated groups. Superoxide dismutase, catalase and reduced glutathione levels also increased significantly $(p<0.01)$ in the extract and GMP treated groups compared to STZ group. The MDA activity however reduced significantly in the extract treated groups comparable to the GMP group. 


\section{8}

Effect of Anacardium occidentale nut extract on Lipid profile in streptozotocin-induced Diabetic rats.

The lipid profile result (Figure 6) showed significant increases in total cholesterol, triglyceride, low density lipoprotein and very low density lipoprotein concentrations in the STZ group when compared to control. The high density lipoprotein concentration however decreased significantly. After treatment of diabetic rats with both doses of the extract, the high density lipoprotein concentration increased significantly while the total cholesterol, triglyceride, low density lipoprotein and very low density lipoprotein concentrations were significantly reduced comparable to the GMP group.

\subsection{Effects of Anacardium occidentale nut extract on Markers of Liver Function in Diabetic Wistar Rats}

There were significant $(p<0.01)$ increases in aspartate aminotransferase (AST), alkaline phosphatase (ALP) and alanine transaminase (ALT) in the STZ group compared to control (Table 3). However, in administration of Anacardium occidentale nut extracts to STZ- induced diabetic rats, apartate aminotransferase, alkaline phosphatase and alanine transaminase activitiesreduced significantly $(p<0.05)$ comparable to the GMP group.

\subsection{Effects of Anacardium occidentale nut extract on Some Markers of Kidney Function in Streptozotocin- Induced Diabetic Rats}

The markers of kidney function assessed in this study were presented in Table 4. The urea, uric acid and creatinine levels in the STZ group increased significantly $(p<0.05)$ compared to control. However, there were significant $(p<0.01)$ reductions in levels of urea, uric acid, and creatinine in the extract and GMP groups compared to STZ group after treatment.

\subsection{Discussion}

\subsection{Discussion}

Diabetes mellitus can be characterized as exposure to hyperglycemia and increase in total lipids, total cholesterol and LDL-cholesterol in diabetic rats which is now recognized as the primary causal factor in the pathogenesis of diabetic complications as well as induce a large number of alterations in vascular tissue that potentially promotes or accelerates atherosclerosis [28]. Hyperglycemia generates reactive oxygen species (ROS), which in turn causes cellular damage in many ways. Damage to the cells ultimately results in secondary complications in diabetes mellitus [29]. The elevations of total lipids are due to the decrease in lipoprotein lipase (LPL) activity secondary to insulin deficiency [30].

In the study of Locke et al. [31], it has been stated that acute oral toxicity studies are performed in animals to evaluate the safety of plant-based products and other formulations for humans [32]. In this study, the non-toxic nature of the methanolic nut extract of Anacardium occidentale was observed by the acute oral toxicity test. The safe doses in animals were extrapolated to human doses, and at the dose level of $100 \mathrm{mg} / \mathrm{kg}$ and $200 \mathrm{mg} / \mathrm{kg}$ of the extract, no mortality or any toxic reactions were found at any of the doses; thus they are used as the low $(100 \mathrm{mg} / \mathrm{kg})$ and high $(200 \mathrm{mg} / \mathrm{kg})$ doses in this study respectively.

The phytochemical constituents available in the methanolic nut extract of Anacardium occidentale in this research work revealed the presence of tannins, terpenoids, and reducing sugar while saponins, phlobotannins, 
cardiac glycosides, anthraquinones, alkaloids, flavonoids and steroids tested were all absent which correlates with the previous research [33].

In the present investigation, weight loss was one of the symptoms noticed after the induction of diabetes with STZ, which showed a significant decrease in body weight, which may be due to increased muscle wasting. STZ, by causing hyperglycemia and hyperinsulinemia causes a decrease in body weight of diabetic rats as reported by [34]. Treatment with Anacardium occidentale nut extract at low $(100 \mathrm{mg} / \mathrm{kg})$ and high $(200 \mathrm{mg} / \mathrm{kg})$ doses for 28 days increase their body weight compared to the levels of untreated diabetic rats.

Fasting blood sugar (FBS) is an important and necessary basal parameter among DM patients [35]. This study showed that Anacardium occidentale nut extract decreased FBS levels and reversed its value in STZ-induced diabetic rats. STZ can damage pancreatic $\beta$-cells and decrease endogenous insulin secretion, thereby reducing glucose utilization of tissues. Therefore, the possible mechanism for decreased lipid levels could either be an insulin-releasing effect of Anacardium occidentale nut extract or insulin-sensitizing activity, because insulin has been proved to inhibit the activity of the hormone-sensitive lipases in adipose tissue and suppresses the release of lipids. The HDL-cholesterol is involved in transport of cholesterol from peripheral tissues to the liver and thereby, it acts as a protective factor. In the present study, the level of HDL-cholesterol was also found to be reduced in diabetic rats. The level of HDL-cholesterol was increased in STZ-induced diabetic rats when treated with Anacardium occidentale methanolic nut extract. This indicates that Anacardium occidentale methanolic nut extract may help to increase transport of peripheral tissue cholesterol to the liver and thereby decrease blood cholesterol levels [36].

The food intake decreased while water intake increased in STZ-induced diabetic rats compared to normal control. Treatment with Anacardium occidentale methanolic nut extract showed increased food intake and decreased water intake in extract-treated rats compared to diabetic control. This is similar to the findings of AlAwwadi et al. [37], who reported that the classical clinical manifestations of diabetes type I, including weight loss, increased food, and water intakes and reduced insulin concentrations in rats administered STZ. This may be due to Anacardium occidentale alleviating the symptoms of type I diabetes mellitus.

The effect of Glimepiride and Anacardium occidentale on FBS was evaluated after the 28 days study period. Both treatments showed $(\mathrm{p}<0.05)$ hypoglycemic activity compared to diabetic control. Experimental animals treated with Anacardium occidentale methanolic nut extract showed a decrease in FBS level but not as much as those treated with standard drugs. Improved blood glucose in the treated animals suggests either increased insulin release or improved insulin activity, both of which could be attributed to improvement in the integrity of $\beta$ - endocrinocytes [38].

GSH, SOD, GPx, and CAT concentration all showed significant $(p<0.05)$ increase in all treated groups as compared with the STZ untreated group. Increase in the level of GSH, SOD, GPx, and CAT concentration may protect the tissues against diabetic associated injury, by reducing the susceptibility to toxic radicals (Inove et al., 1987) [39]. This research work hence showed that Anacardium occidentale methanolic nut extract contains some components, especially antioxidants capable of suppressing oxidative stress.

\subsection{Conclusion}


Administration of Anacardium occidentale methanolic nut extract exerts significant antidiabetic, anti-oxidative, and anti-hyperlipidemic effects as well as improvement in liver and kidney functions in STZ-induced diabetic rats. Anacardium occidentale methanolic nut extract can therefore be a therapeutic application for diabetes mellitus. There is a need for further studies to confirm the mechanism of actions and isolate the active ingredients of this extract so as to develop it as a potent antidiabetic formulation.

\section{Abbreviations}

AST: Aspartate aminotransferase; ALT: Alanine aminotransferase; ALP: Alkaline phosphatase; TP: Total protein; SOD: Superoxide dismutase; CAT: Catalase; GPx: Glutathione peroxidase; GSH: Reduced glutathione; MDA: Malondialdehyde; CON: Control; STZ: Streptozotocin; GMP: Glimepiride; ROS: Reactive oxygen species; TC: Total cholesterol; TG: Triglycerides; HDL-c: High density lipoprotein-cholesterol; LDL-c: Low density lipoproteincholesterol; VLDL-c : Very low density lipoprotein-cholesterol.

\section{Declarations}

\section{Ethics approval and consent to participate:}

All procedure were approved by the Animal care committee of the Ladoke Akintola University of Technology and conducted according to the "Principles of Laboratory Animal Care" and specific national laws where applicable.

Consent for publication: Not applicable

\section{Availability of data and Materials:}

The datasets used and/ or analysed during this current study are included in this manuscripts.

\section{Competing interests:}

No competing interests

\section{Funding:}

This research work did not receive any specific funding

\section{Authors' contributions:}

All authors have made considerable contribution to the work and approved the final version of the publication. FO, MA, and MO carried out the experiment. MO wrote the manuscript with the support of FO. FO supervised the project. MA conceived the original idea.

Acknowledgements: Not applicable

\section{References}

1. International Diabetes Federation. IDF Diabetes Atlas, 8th ed. Brussels, Belgium: International Diabetes Federation; 2017. https://www.idf.org/e-library/epidemiology-research/diabetes-atlas 
2. International Diabetes Federation (2011). IDF Diabetes Atlas $5^{\text {th }}$ pp 45https://www.idf.org/elibrary/epidemiology-research/diabetes-atlas/20-atlas-5th-edition.html

3. American Diabetes Association (2012)."Diagnosis and classification of diabetes mellitus,” Diabetes Care35 (1): S64-S71.https://doi.org/10.2337/dc12-s064

4. W Todd Cade (2008). Diabetes-related Microvascular and Macrovascular Diseases in the Physical Therapy Setting. Phys Ther 88(11):1322-1335.https://doi.org/10.2522/ptj.20080008

5. American Diabetes Association (2009).Diagnosis and Classification of Diabetes Mellitus. Diabetes Care. 32(1): S62-S67. https://doi.org/10.2337/dc09-S062

6. Jaganjac M, Tirosh O, Cohen G, Sasson S, Zarkovic, N (2013). "Reactive aldehydes-second messengers of free radicals in diabetes mellitus," Free Radical Research,47(1): 3948.https://doi.org/10.3109/10715762.2013.789136

7. Lipinski B. (2001). Pathophysiology of oxidative stress in diabetes mellitus.J. Diabetes its Complications 15 (4): 203-210.DOI: 1016/s1056-8727(01)00143-x

8. Pham-Huy LA, He H, Pham-Huy C. (2008).Free radicals, antioxidants in disease and health. IJBS 4 (2): 8996.PMC3614697

9. Giugliano D, Ceriello A, and Paolisso G, (1996) Oxidative stress and diabetic vascular complications.Diabetes Care 19: 257-267. DOI: 10.2337/diacare.19.3.257

10. Quiles JC, Mesa MD, Ramirez-Tortosa CL, Auiglera CM, Battino M, Gi IA, Ramirez-Tortosa MC (2002). Curcuma longa extract supplementation reduces oxidative stress and attenuates aortic fatty streak development in rabbits. ArteriosclerTrombVascBiol. 22: 1225DOI: 10.1161/01.atv.0000020676.11586.f2

11. Marín-Peñalver JJ, Martín-Timón I, Sevillano-Collantes C, and del Cañizo-Gómez, FJ (2016). Update on the treatment of type 2 diabetes mellitus. World J. Diabetes, 7, 354-395.

12. Paris R, Plat M, Giono-Barder P, Linhard J, Laurens A (1977).Recherchechimique etpharmacologiquesur les feuillesd'Anacardiumoccidentale. Bull la SociétédeMédecine d'Afrique Noire Lang Française.22:275281.http://pascal-francis.inist.fr/vibad/index.php?action=getRecordDetail\&idt=PASCAL7850211646

13. Souza MQ, Teotônio IMSN, de Almeida FC, Heyn GS, Alves PS, Romeiro LAS, and Pratesi, C B (2018). Molecular evaluation of anti-inflammatory activity of phenolic lipid extracted from cashew nut shell liquid (CNSL). BMC Complementary and Alternative Medicine, 18(1), 1-11. doi: 10.1186/s12906-018-2247-0

14. Adriano-Anaya L, Trejo-Roblero G, Rosas-Quijano R, Velázquez-Ovalle G, and Vázquez-Ovando A (2017). Mejoramiento del rendimiento y calidad del fruto y pseudofruto de marañonL. con un ciclo de fertilización orgánica. Revista Brasileira de Fruticultura, 39(5), 674. doi: 10.1590/0100-29452017674

15. Montanari RM, Barbosa LCA, Demuner A.J, Silva C J, Andrade NJ, Ismail FMD, and Barbosa MC A (2012). Exposure to anacardiaceae volatile oils and their constituents induces lipid peroxidation within food-borne bacteria cells. Molecules, 17(8), 9728-9740. doi: 10.3390/molecules17089728

16. Silva MI G, Melo CTV De, Vasconcelos LF, Carvalho A MR De, and Sousa FCF (2012). Bioactivity and potential therapeutic benefits of some medicinal plants from the Caatinga (semi-arid) vegetation of Northeast Brazil: a review of the literature. Revista Brasileira de Farmacognosia, 22(1), 193-207. doi: 10.1590/S0102-695X2011005000171

17. Mustapha AA, Owuna G, Ogaji JO, Is-haq UI, and Idris MM (2015). Phytochemical screening and inhibitory activities of Anacardium occidentale leaf extracts against some clinically important bacterial isolates. 
International Journal of Pharmacognosy and Phytochemical Research. 7(2):365-369.

18. Fazali F, Zulkhairi A, Nurhaizan ME, Kamal NH, Zamree MS, and Shahidan MA (2011). Phytochemical Screening, in vitro and in vivo Antioxidant Activities of Aqueous Extract of Anacardium occidentale and its Effects on Endogenous Antioxidant Enzymes in Hypercholesterolemic Induced Rabbits. Res. J. Biol. Sci. $6(2): 69-74$.

19. Ojewole JA (2003): Laboratory evaluation of the hypoglycemic effect of Anacardium occidentale Linn (Anacardiaceae) stem-bark extracts in rats. Methods Find Exp Clin Pharmacol 25: 199-204.

20. Felcman J, and Braganca ML (1987).Chromium in plants: comparison between the concentration of chromium in Brasiliannonhypo and hypoglycemic plants. Biol Trace Elem Res.;17:1116https://doi.org/10.1007/BF02795443

21. Gupta M, Arias T, Correa M and Lamba S (1979).Ethnopharmacognostic observations on Panamanian medicinal plants.J Crude Drug Res17:115-130.https://doi.org/10.3109/13880207909065163

22. Committee for the Update of the Guide for the Care and Use of Laboratory Animals Institute for Laboratory Animal Research Division on Earth and Life Studies. Guide for the Care and Use of Laboratory Animals. In: National Research Council of the National Academies. 8th ed. Washington DC: The National Academies Press; 2011.

23. Harwood L, Moody M, Christopher J (1989). Experimental organic chemistry: Principles and Practice. WileyBlackwell., pp 122-125.https://www.wiley.com/en-us/Experimental+Organic+Chemistry\%2C+3rd+Edition-p9781119952381

24. Sofowora, A. (1993). Medicinal Plants and Traditional Medicinal in Africa. Screening Plants for Bioactive Agents, 2nd Edn, Ibadan: Spectrum books limited. doi: 10.1016/S0378-8741(99)00136-1

25. Trease GE, Evans WC (2002). Pharmacognosy, 15th Edn, London: Saunders Publishers.

26. Lorke D (1983). A new approach to practical acute toxicity testing. Arch Toxicol. 1983;54:275871007/BF01234480

27. Gupta R, Gupta RS (2009). Protective Role of Pterocarpus marsupium in Diabetes-Induced Hyperlipidemic Condition. Journal of Complementary and Integrative Medicine 6 (1): 21DOI: https://doi.org/10.2202

28. Trinder P (1969). Determination of Blood Glucose Using an Oxidase-Peroxidase System With a NonCarcinogenic Chromogen. J Clin Pathol 22(2):158-61.doi: 1136/jcp.22.2.158

29. Burtis C, Ashood E (1999). Text book of clinical chemistry. 3th ed. London. Vol.2 Chapter 33:1145$1150.1007 / \mathrm{s} 12291-012-0287-7$

30. American Diabetes Association (2014) Standards of Medical Care in Diabetes. Diabetes Care 37(1):S14S80https://doi.org/10.2337/dc14-S014

31. Hunt JV, Dean RT and Wolff SP (1988). "Hydroxyl radical production and antioxidativeglycosylation".Glucose autoxidation as the cause of protein damage in the experimental glycation model of diabetes mellitus and aging. Biochemical journal. 256(1): 205-212doi: 1042/bj2560205

32. Minnich A, Zilversmit DB (1989). Impaired triacylglycerol catabolism in hypertriglyceremia of the diabetic, cholesterol fed rabbit: A possible mechanism for protection from atherosclerosis. Biochem. Biophys. Acta. 1002: 324-332https://doi.org/10.1016/0005-2760(89)90346-9

33. Akah PA, Okafor CL (1992). Blood sugar lowering effect of Vernonia amygdalina Del, in an experimental rabbit model. Phytotherapy research 6 (3):117-173, 1992 https://doi.org/10.1002/ptr.2650060318 
34. Swanston-Flatt SK, Day C, Flatt PR, Gould BJ, Bailey CJ. (1989).Glycaemic effects of traditional European plant treatments for diabetes. Studies in normal and streptozotocin diabetic mice. Diabetes Res.10(2):6973.PMID: 2743711

35. Tang H, Li D, Li Y,Zhang X,Song Y,and Li X (2018). Effects of Vitamin D Supplementation on Glucose and Insulin Homeostasis and Incident Diabetes among Nondiabetic Adults: A Meta-Analysis of Randomized Controlled Trials.Int J Endocrinol 2018(1):1-9https://doi.org/10.1155/2018/7908764

36. Tuteja S, Rader DJ (2014). High-density lipoproteins in the prevention of cardiovascular disease: changing the paradigm. Clin Pharmacol Ther, 96(1): 48-56DOI: 1038/clpt.2014.79 ·

37. Al-Awwadi N A, Bornet A, Azay J, Araiz C, Delbosc S, Cristol JP,Teissedre PL(2004). Red wine polyphenols alone or in association with ethanol prevent hypertension, cardiac hypertrophy, and production of reactive oxygen species in the insulin-resistant fructose-fed rat. Journal of Agricultural and Food Chemistry, 52(18), 5593-55971021/jf049295g

38. Snigur GL, Samokhina MP, Pisarev VB, Spasov AA and Bulanov AE(2008) Structural alterations in pancreatic islets in streptozotocin-induced diabetic rats treated with bioactive additive on the basis of Gymnema sylvestre. Morfologiia, 133(1): 60-4.https://europepmc.org/article/med/19069418

\section{Tables}

Table 1. Preliminary phytochemical analysis of Anacardium occidentale nut extract.

\begin{tabular}{|l|l|l|}
\hline S/N & METABOLITES & NUT \\
\hline $\mathbf{1}$ & Saponin & - \\
\hline $\mathbf{2}$ & Flavonoids & - \\
\hline $\mathbf{3}$ & Tannin & + \\
\hline $\mathbf{4}$ & Phlobatannin & - \\
\hline $\mathbf{5}$ & Steroids & - \\
\hline $\mathbf{6}$ & Terpenoids & + \\
\hline $\mathbf{7}$ & Cardiac Glycosides & - \\
\hline $\mathbf{8}$ & Anthraquinones & - \\
\hline $\mathbf{9}$ & Alkaloids & - \\
\hline $\mathbf{1 0}$ & Reducing Sugar & + \\
\hline
\end{tabular}

Key

$(-)$ means not present

(+) means present 
Table 2: $\quad$ Effects of Anacardium occidentale nut extract on Antioxidant Enzymes and Oxidative Stress Parameters in Streptozotocin-Induced Diabetic Rats

\begin{tabular}{|c|c|c|c|c|c|}
\hline PARAMETERS & $\mathrm{CON}$ & STZ & $100 \mathrm{mg} / \mathrm{kg}$ & $200 \mathrm{mg} / \mathrm{kg}$ & GMP \\
\hline SOD $(\mu / \mathrm{ml})$ & $1.83 \pm 0.02$ & $0.79 \pm 0.01 *$ & $1.62 \pm 0.05^{\#}$ & $1.55 \pm 0.02^{\#}$ & $1.67 \pm 0.01^{\#}$ \\
\hline GPx (U/L) & $51.01 \pm 1.91$ & $24.00 \pm 2.07 *$ & $59.27 \pm .1 .40^{\#}$ & $55.14 \pm 2.43^{\#}$ & $66.02 \pm 2.27^{\#}$ \\
\hline MDA $(\mu \mathrm{M})$ & $6.74 \pm 0.80$ & $11.75 \pm 0.57 *$ & $6.73 \pm 0.60^{\#}$ & $6.63 \pm 0.78^{\#}$ & $3.37 \pm 0.06^{\#}$ \\
\hline GSH $\quad(\mathrm{mM})$ & $2.62 \pm 0.13$ & $1.52 \pm 0.03^{*}$ & $2.49 \pm 0.28^{\#}$ & $3.35 \pm 0.18^{\#}$ & $2.30 \pm 0.17$ \\
\hline $\mathrm{CAT}(\mathrm{mol} / \mathrm{ml} / \mathrm{min})$ & $24.67 \pm 0.63$ & $12.40 \pm 0.32^{* *}$ & $27.18 \pm 1.79^{\#}$ & $34.04 \pm 1.84^{\#}$ & $31.13 \pm 0.85^{\#}$ \\
\hline
\end{tabular}

Values are expressed as mean \pm SEM $(n=8) . *_{-}$significant at $p<0.05$ compared with control, \# significant at $p<0.05$ compared with $S T Z$ group

LEGEND: CON- Control, STZ- Streptozotocin, GMP- glimepiride, SOD-Superoxide dismutase, GPx- Glutathione peroxidase, MDA-Malondialdehyde, GSH-Glutathione, CATCatalase.

Table 3: $\quad$ Effects of Anacardium occidentale nut extract on Markers of Liver function in Streptozotocin-Induced Diabetic Rats 


\begin{tabular}{|l|l|l|l|l|l|}
\hline PARAMETERS & CON & STZ & $100 \mathrm{mg} / \mathrm{kg}$ & $200 \mathrm{mg} / \mathrm{kg}$ & GMP \\
\hline AST (U/L) & $117.9 \pm 11.27$ & $300.7 \pm 19.52^{*}$ & $122.3 \pm 6.83^{\#}$ & $123.3 \pm 13.1^{\#}$ & \\
\hline ALP (U/L) & $326.8 \pm 15.65$ & $584.6 \pm 52.37^{*}$ & $245.4 \pm .17 .29^{\#}$ & $288.9 \pm 18.18^{\#}$ & \\
\hline & & & & & $135.7 \pm 24.55^{\#}$ \\
ALT (U/L) & $43.75 \pm 3.88$ & $95.67 \pm 1.61^{*}$ & $37.55 \pm 1.28^{\#}$ & $45.71 \pm 2.66^{\#}$ & \\
& & & & & $34.60 \pm 5.37^{\#}$ \\
\hline
\end{tabular}

Values are expressed as mean \pm SEM $(n=8) . *_{-}$significant at $p<0.05$ compared with control, \# significant at $p<0.05$ compared with $S T Z$ group

LEGEND: CON- Control, STZ- Streptozotocin, GMP- glimepiride, AST- apartate aminotransferase, ALP- Alkaline phosphatase, ALT- Alanine transaminase.

Table 4: $\quad$ Effects of Anacardium occidentale nut extract on Markers of Kidney function in Streptozotocin-Induced Diabetic Rats

\begin{tabular}{|l|l|l|l|l|l|}
\hline PARAMETERS & CON & STZ & $100 \mathrm{mg} / \mathrm{kg}$ & $200 \mathrm{mg} / \mathrm{kg}$ & GMP \\
\hline UREA (mg/dl) & $20.76 \pm 0.24$ & $66.68 \pm 5.30^{*}$ & $30.62 \pm 0.48^{\#}$ & $23.46 \pm 2.77^{\#}$ & $23.03 \pm 0.29^{\#}$ \\
\hline $\begin{array}{l}\text { URIC ACID } \\
\text { (mg/dl) }\end{array}$ & $326.8 \pm 15.65$ & $584.6 \pm 52.37^{*}$ & $245.4 \pm .17 .29^{\#}$ & $288.9 \pm 18.18^{\#}$ & $135.7 \pm 24.55^{\#}$ \\
\hline $\begin{array}{l}\text { CREATININE } \\
\text { (umol/l) }\end{array}$ & $43.75 \pm 3.88$ & $95.67 \pm 1.61^{*}$ & $37.55 \pm 1.28^{\#}$ & $45.71 \pm 2.66^{\#}$ & $34.60 \pm 5.37^{\#}$ \\
\hline
\end{tabular}

Values are expressed as mean \pm SEM $(n=8) . *_{-}$significant at $p<0.05$ compared with control, \#significant at $p<0.05$ compared with STZ group 
LEGEND: CON- Control, STZ- Streptozotocin, GMP- glimepiride.

\section{Figures}

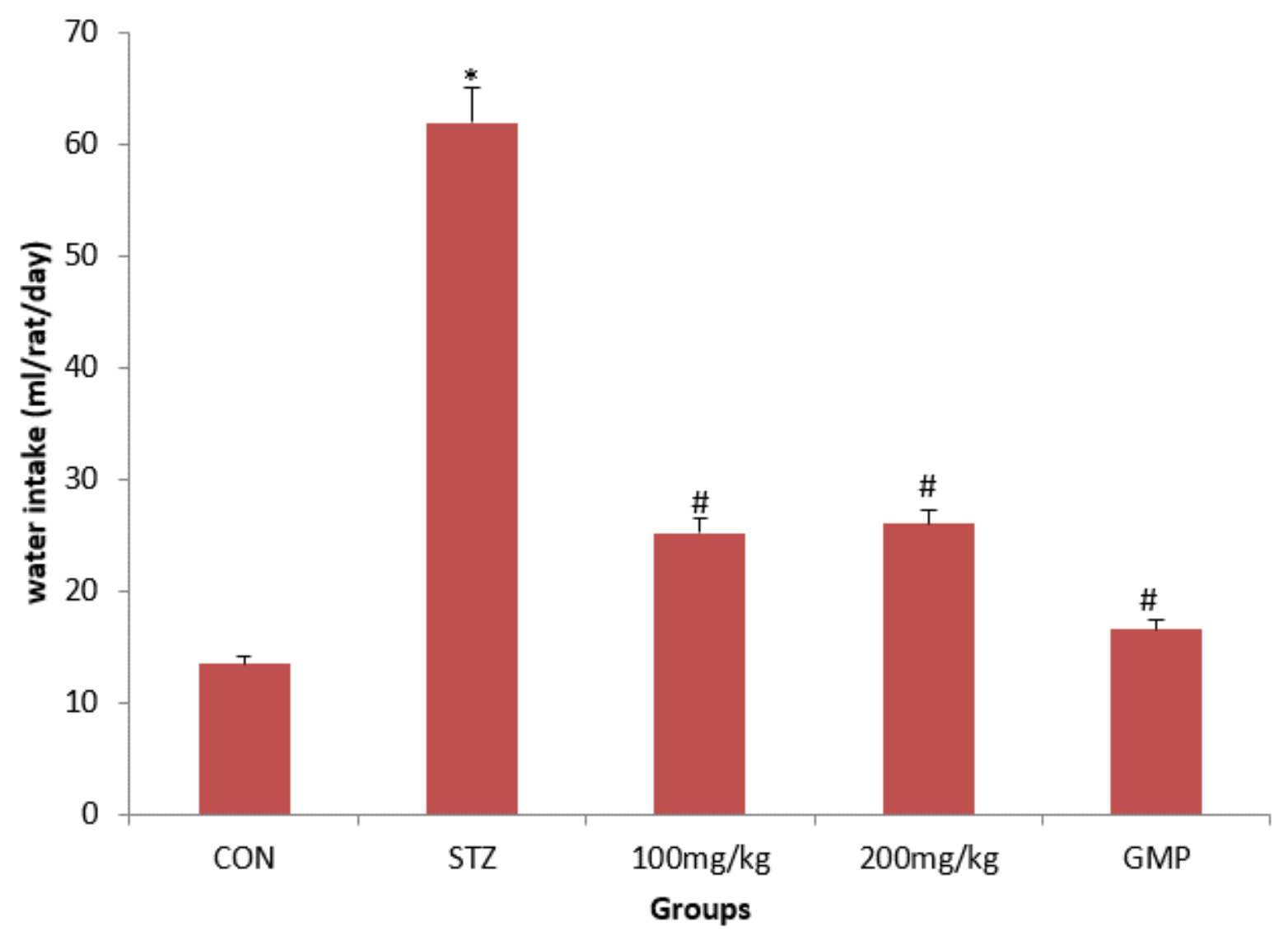

\section{Figure 1}

Effects of Anacardium occidentale nut extract on water intake in streptozotocin-induced diabetic rats. Values are expressed as mean \pm SEM $(n=8)$. *significant at $p<0.05$ compared with control, \#significant at $p<0.05$ compared with STZ group. Key: CON- Control group STZ- Streptozotocin-induced untreated group GMPGlimepiride treated group 


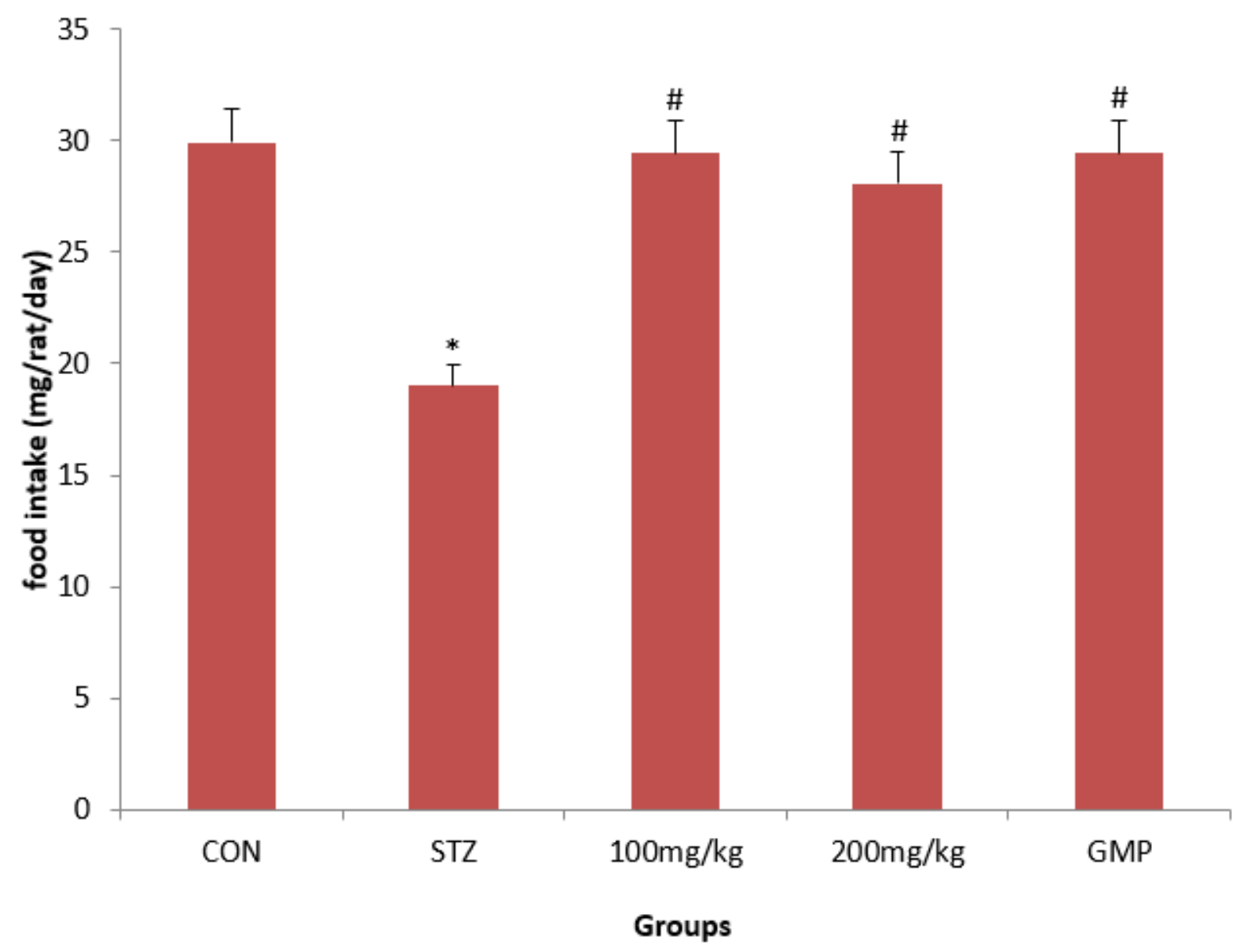

Figure 2

Effects of Anacardium occidetanle nut extract on food intake in Streptozotocin-induced diabetic rats. Values are expressed as mean \pm SEM $(n=8)$. *significant at $p<0.05$ compared with control, \#significant at $p<0.05$ compared with STZ group. Key: CON- Control group STZ- Streptozotocin-induced untreated group GMPGlimepiride treated group 


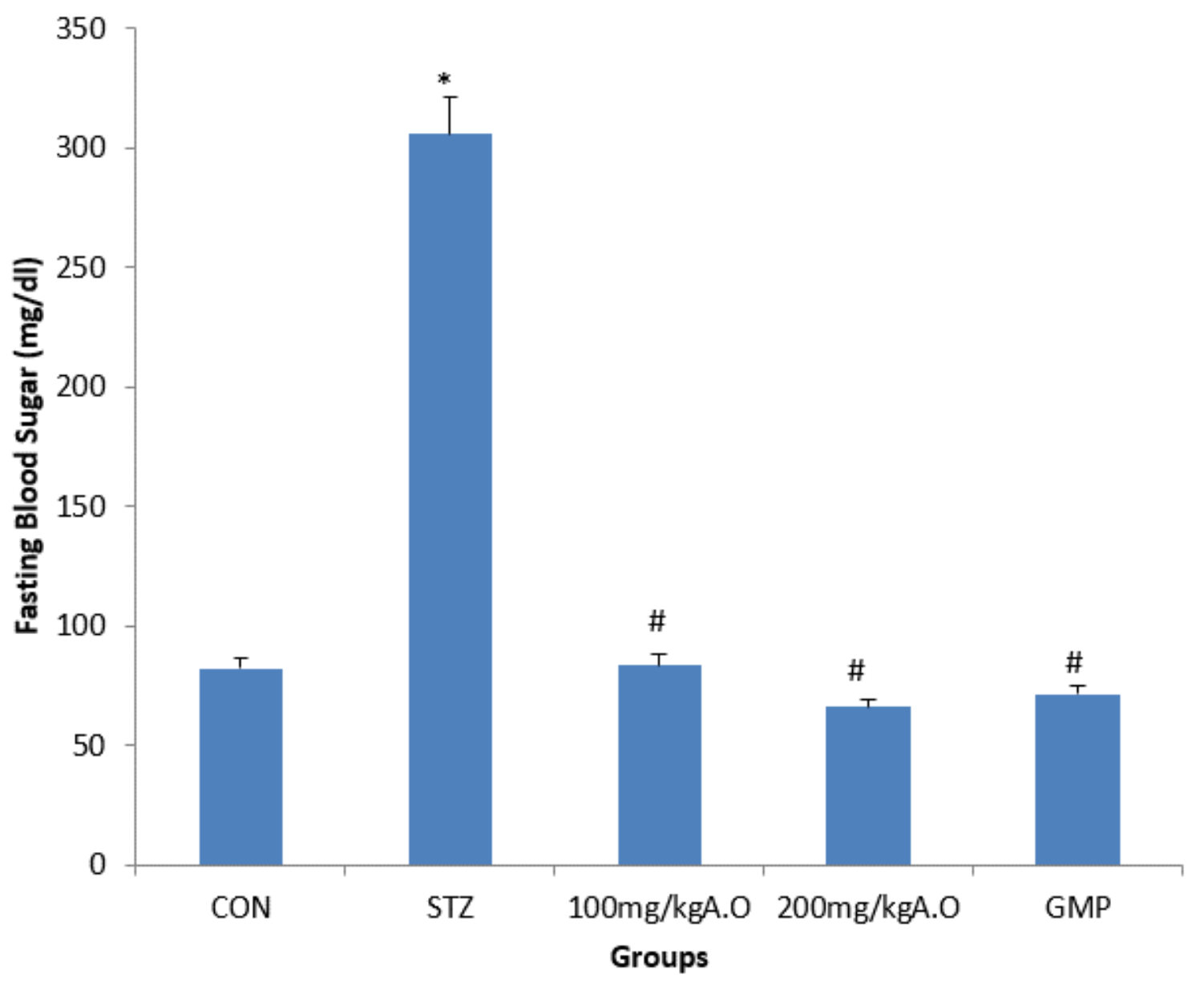

Figure 3

Effects of Anacardium occidentale nut extract on fasting blood sugar in Streptozotocin-induced diabetic rats. Values are expressed as mean \pm SEM $(n=8)$. *significant at $p<0.05$ compared with control, \#significant at p $<0.05$ compared with STZ group. Key: CON- Control group STZ- Streptozotocin-induced untreated group GMPGlimepiride treated group 


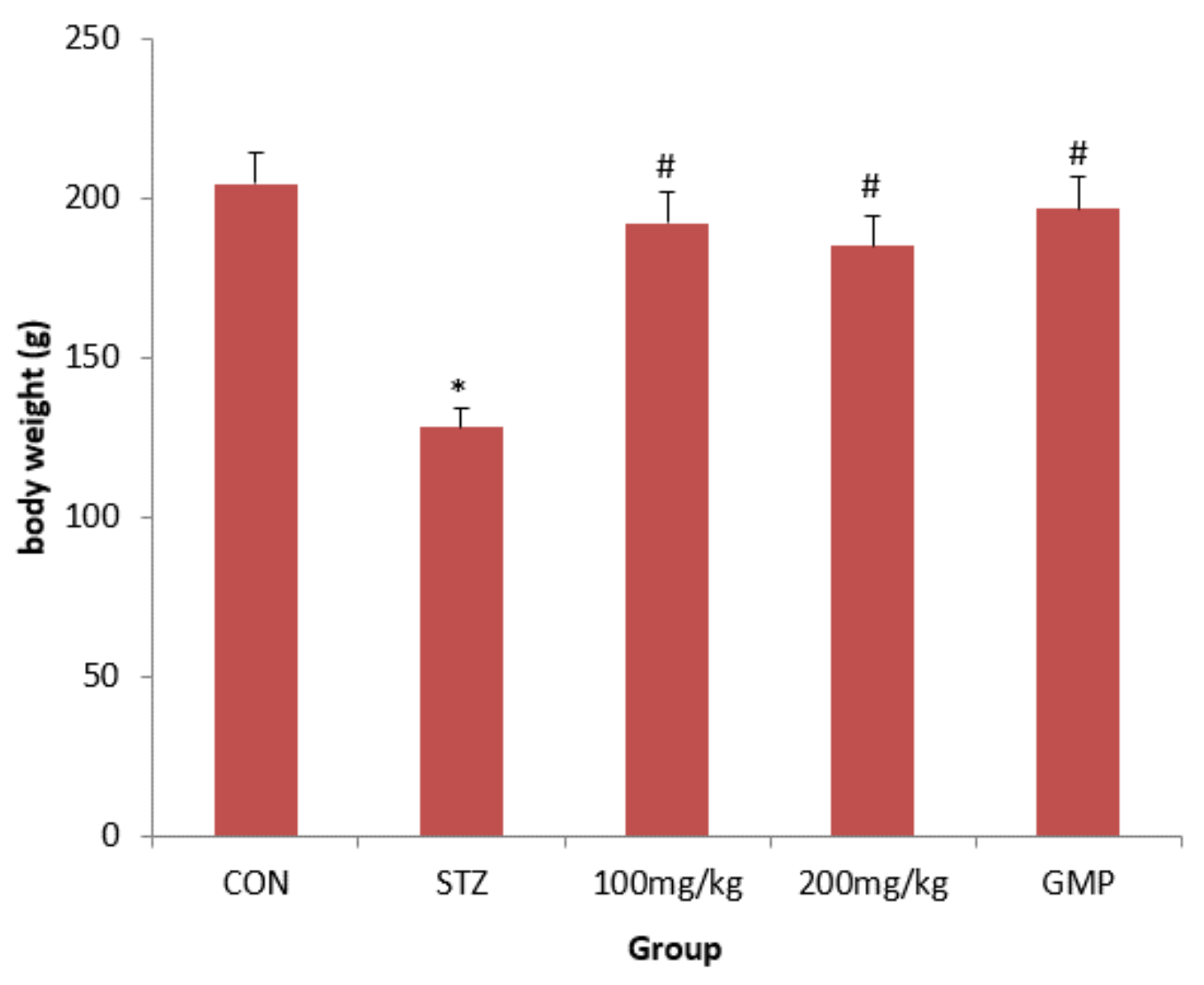

Figure 4

Effects of Anacardium occidentale nut extract on body weight in streptozotocin-induced diabetic rats. Values are expressed as mean \pm SEM $(n=8)$. *significant at $p<0.05$ compared with control, \#significant at $p<0.05$ compared with STZ group. Key: CON- Control group STZ-Streptozotocin-induced untreated group GMPGlimepiride treated group 


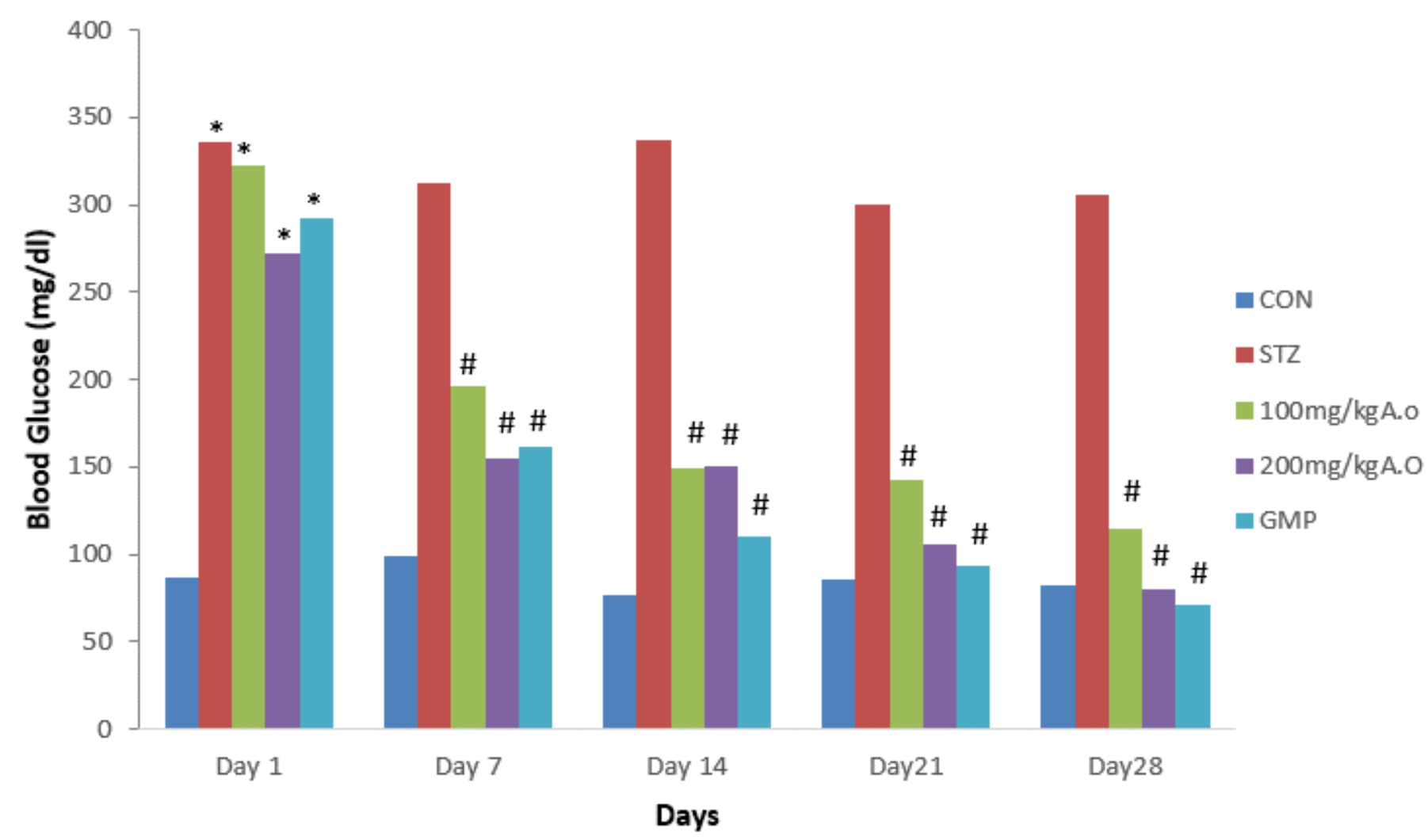

\section{Figure 5}

Effects of Anacardium occidentale nut extract on weekly blood glucose levels in streptozotocin-induced diabetic rats. Values are expressed as mean \pm SEM $(n=8)$. *significant at $p<0.05$ compared with control, \#significant at $p<0.05$ compared with STZ group. Key: CON-Control group STZ-Streptozotocin-induced untreated group GMP- Glimepiride treated group 


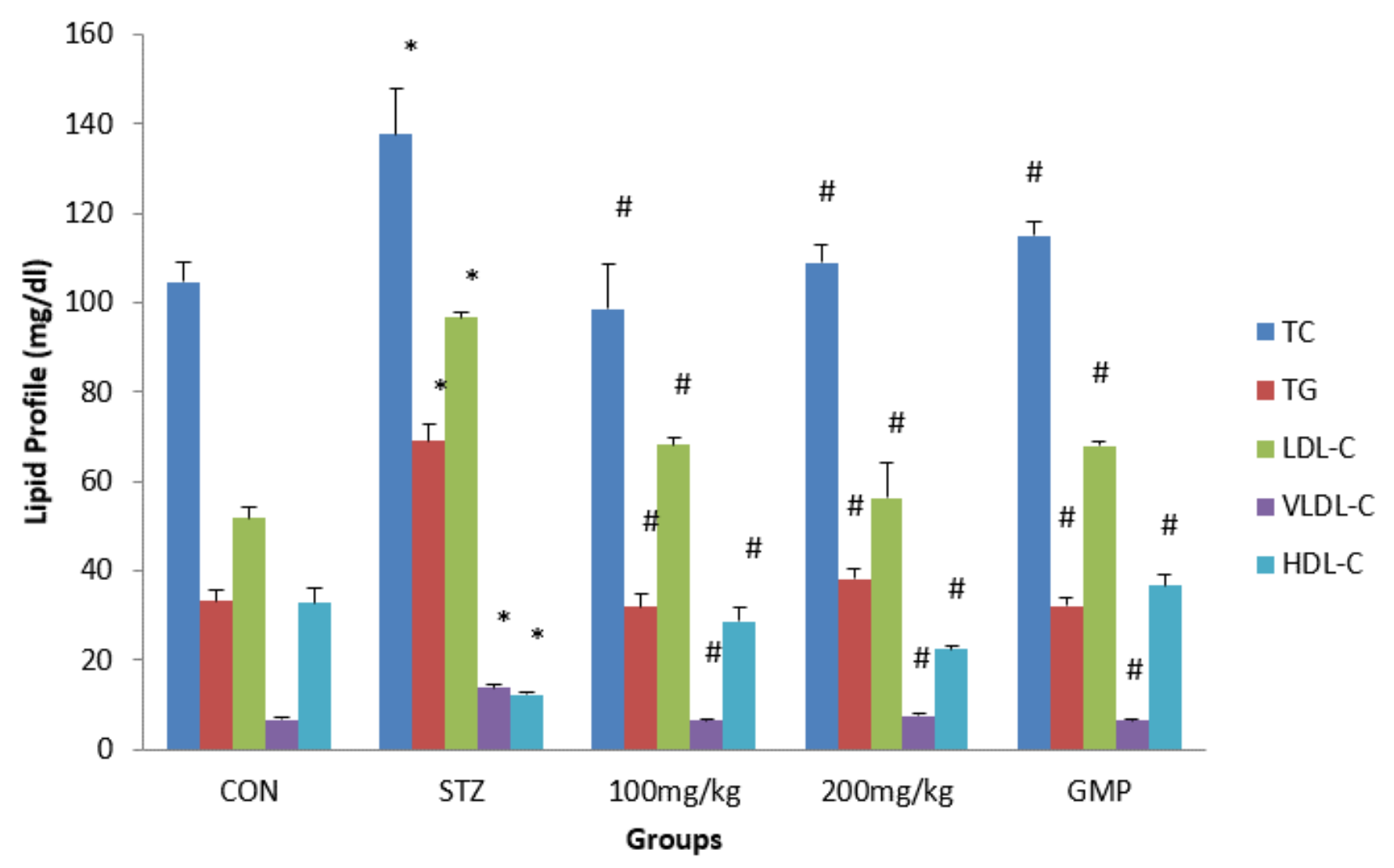

Figure 6

Effect of Anacardium occidentale nut extract on Lipid profile in streptozotocin-induced diabetic rats. Values are expressed as mean \pm SEM $(n=8)$. * significant at $p<0.05$ compared with control, \#significant at $p<0.05$ compared with STZ group. Key: CON- Control group STZ- Streptozotocin-induced untreated group GMP- Glimepiride treated group 